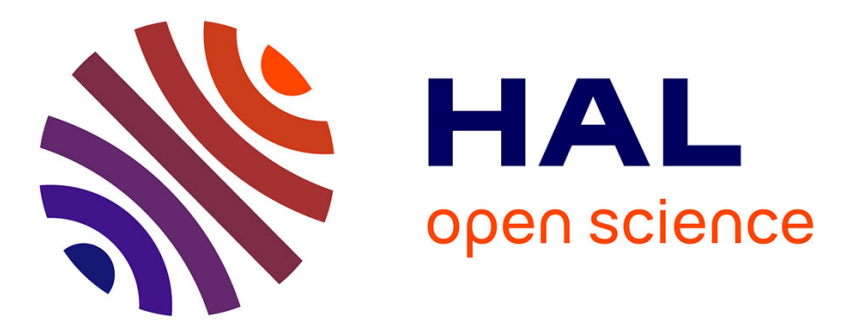

\title{
Hyperexcitability and seizures in the THY-Tau22 mouse model of tauopathy
}

\author{
Victoria Gomez-Murcia, Ursula Sandau, Barbara Ferry, Sandrine Parrot, \\ Cyril Laurent, Marie Basquin, Luc Buée, Detlev Boison, David Blum
}

\section{- To cite this version:}

Victoria Gomez-Murcia, Ursula Sandau, Barbara Ferry, Sandrine Parrot, Cyril Laurent, et al.. Hyperexcitability and seizures in the THY-Tau22 mouse model of tauopathy. Neurobiology of Aging, 2020, 94, pp.265-270. 10.1016/j.neurobiolaging.2020.06.004 . hal-03065490

\author{
HAL Id: hal-03065490 \\ https://hal.science/hal-03065490
}

Submitted on 12 Oct 2021

HAL is a multi-disciplinary open access archive for the deposit and dissemination of scientific research documents, whether they are published or not. The documents may come from teaching and research institutions in France or abroad, or from public or private research centers.
L'archive ouverte pluridisciplinaire HAL, est destinée au dépôt et à la diffusion de documents scientifiques de niveau recherche, publiés ou non, émanant des établissements d'enseignement et de recherche français ou étrangers, des laboratoires publics ou privés. 


\title{
Hyperexcitability and seizures in the THY-Tau22 mouse model of tauopathy
}

\author{
Victoria Gomez-Murcia ${ }^{\mathrm{a}, \mathrm{b}, \#}$, Ursula Sandau ${ }^{\mathrm{c}, \#}$, Barbara Ferry ${ }^{\mathrm{d}}$, Sandrine Parrot ${ }^{\mathrm{d}}$, \\ Cyril Laurent ${ }^{\mathrm{a}}$, Marie Basquin ${ }^{\mathrm{a}}$, Luc Buée ${ }^{\mathrm{a}}$, Detlev Boison ${ }^{\mathrm{e}, *, *}$, David Blum $^{\mathrm{a}, *, \#}$ \\ ${ }^{a}$ University of Lille, Inserm, CHU Lille, U1172 - LilNCog - Lille Neuroscience E Cognition, Lille, France \\ b Alzheimer \& Tauopathies, LabEx DISTALZ, LiCEND, Lille, France \\ ${ }^{c}$ Department of Anesthesiology and Perioperative Medicine, Oregon Health and Sciences University, Portland, OR, USA \\ ${ }^{\mathrm{d}}$ Centre of Research in Neuroscience Lyon, CNRS UMR 5292 - INSERM U 1028 - Université Claude Bernard Lyon 1, Bron, France \\ ${ }^{\mathrm{e}}$ Department of Neurosurgery, Robert Wood Johnson Medical School, Rutgers University, Piscataway, NJ, USA
}

\section{A R T I C L E I N F O}

\section{Article history:}

Received 1 April 2020

Received in revised form 20 May 2020

Accepted 5 June 2020

Available online 20 June 2020

\section{Keywords:}

Alzheimer's disease

THY-Tau22

Tau

EEG

Epilepsy

Seizures

\begin{abstract}
A B S T R A C T
Epileptic seizures constitute a significant comorbidity of Alzheimer's disease (AD), which are recapitulated in transgenic mouse models of amyloidogenesis. Here, we sought to evaluate the potential role of tau pathology regarding seizure occurrence. To this end, we performed intra-hippocampal electroencephalogram (EEG) recordings and PTZ (pentylenetetrazol) seizure threshold tests in THY-Tau22 transgenic mice of $\mathrm{AD}$-like tau pathology. We demonstrate that despite a lack of spontaneous epileptiform activity in Tau22 mice, the animals display increased PTZ-induced seizure susceptibility and mortality. The increased propensity for induced seizures in THY-Tau22 mutants correlates with astrogliosis and increased expression of adenosine kinase, consistent with increased network excitability. These data support an impact of tau pathology toward AD-associated seizures and suggest that tau pathology may contribute to seizure generation in $A D$ independent of $A \beta$ pathology.
\end{abstract}

(c) 2020 Elsevier Inc. All rights reserved.

\section{Introduction}

The microtubule-associated protein tau is a scaffolding protein, largely expressed by neurons (Arendt et al., 2016). Under pathological conditions, tau undergoes several modifications that are thought to impair brain function and to cause neurodegeneration. Neurofibrillary tangles, made of hyperphosphorylated and aggregated Tau proteins ("Tau pathology") are hallmarks of Alzheimer's disease (AD) and other dementia, particularly some subtypes of frontotemporal lobar degenerations (FTLDs; Lebouvier et al., 2017; Sergeant et al., 2008). In AD, neuronal Tau pathology initially appears at very circumscribed brain regions and subsequently progresses throughout the brain in a fairly predictive stereotypical pattern. Topographical spread of Tau pathology has been linked to

\footnotetext{
* Corresponding author at: Inserm UMR-S1172, “Alzheimer \& Tauopathies”, Place de Verdun, 59045 Lille, Cedex, France. Tel +33320298850; fax: +33320538562.

** Corresponding author at: Department of Neurosurgery, Robert Wood Johnson Medical School, Rutgers University, 683 Hoes Lane West, Piscataway, NJ 08854, USA. Tel.: +1 732235 6373; fax: +1 7323576710 .

E-mail addresses: detlev.boison@rutgers.edu (D. Boison), david.blum@inserm.fr (D. Blum).

\# Equal contributions.
}

progressive cognitive deterioration (Bejanin et al., 2017; Brier et al., 2016; Colin et al., 2020; Duyckaerts et al., 1997). All these observations support a pivotal contribution of neuronal Tau pathology to cognitive deficits. However, mechanisms underlying neuronal Tau pathology-induced cognitive deficits in AD remain poorly understood (Guo et al., 2017; Wang and Mandelkow, 2016).

Epileptic seizures and subclinical epileptiform activity constitute a frequent and severe comorbidity of $A D$, that might have an impact on cognitive status (Lam et al., 2017; reviewed in the study by Vossel et al., 2017). The incidence of seizures has also been described in patients with different types of FTLD including those with MAPT mutations (reviewed in the study by Sánchez et al., 2018). Obvious evidence speaks for a link between Tau and seizure occurrence. First, Tau hyperphosphorylation and misfolding have been observed in patients with epilepsy as well as in different related experimental models (reviewed in the study by Sánchez et al., 2018). Second, Tau reduction limits excessive network excitability in various experimental models of seizures (DeVos et al., 2013; Gheyara et al., 2014; Holth et al., 2013; Ittner et al., 2010; Roberson et al., 2007). Whether Tau pathology itself promotes the development of seizures independent of $A \beta$, and whether it correlates to memory deficits, remains unclear. Few studies have been 
performed in models of tauopathy overexpressing human Tau protein bearing FTLD-MAPT-related mutations (García-Cabrero et al., 2013; Maeda et al., 2016; Van Erum et al., 2020). Overall, these studies demonstrate a higher susceptibility to the proconvulsant $\mathrm{GABA}_{\mathrm{A}}$ receptor antagonist pentylenetetrazol (PTZ) as compared to wild-type littermate mice. However, presence of spontaneous epileptiform activity and occurrence of these latter phenomena earlier or concomitantly to memory impairments remain unclear. In the present study, we evaluated the impact of Tau pathology toward spontaneous electrographic seizure occurrence and the response of seizure thresholds to PTZ using the THYTau22 mouse model of tauopathy, known to progressively develop hippocampal Tau pathology together with spatial memory impairments (Burnouf et al., 2013; Van der Jeugd et al., 2013).

\section{Methods}

Male THY-Tau22 (Tau22) and littermate wild-type (WT) mice, taken as controls [pure C57Bl6/J background], were kept in standard animal cages as described (Schindowski et al., 2006). Experiments were performed in an AAALAC-accredited facility in compliance with the principles outlined in the NIH Guide for the Care and Use of Laboratory animals and under approval by the Institutions Animal Care and Use Committee.

EEG electrodes were implanted in THY-Tau22 mice and agematched WT littermates at $6(\mathrm{n}=7 /$ genotype $)$ and 12 months of age ( $\mathrm{n}=4 \mathrm{WT}$ and $\mathrm{n}=9$ Tau22). Briefly, each mouse was anesthetized (1.5\%-2\% isoflurane) and equipped with (1) a bipolar stainless steel electrode (insulated except for $80-100 \mu \mathrm{m}$ vertically exposed at the tip; tip diameter $5-\mu \mathrm{m}$; vertical tip separation 200-250 $\mu \mathrm{m}$; Plastics One Inc) unilaterally implanted into the hippocampal CA1 subregion using stereotactic coordinates $(\mathrm{AP}=-2.1 \mathrm{~mm} ; \mathrm{ML}=-1.8 \mathrm{~mm} ; \mathrm{DV}=-1.7 \mathrm{~mm}$ with bregma as reference); (2) a cortical monopolar screw electrode placed over the frontal cortex; (3) and a monopolar screw ground electrode over the cerebellum. All electrodes were secured to the skull with dental cement. After recovery from surgery, all animals were continuously recorded by EEG for at least 72 hours. Electrical brain activity was monitored using a Nervus EEG recording system connected with a Nervus Magnus 32/8 Amplifier. The digital EEG signal was bandpass filtered (high-pass filter $1.0 \mathrm{~Hz}$ cut off, low-pass $50 \mathrm{~Hz}$ ) and analyzed using the LabChart version 7 software (AD Instruments). EEGs were assessed for seizure activity as defined as highamplitude rhythmic discharges that represented a new pattern of tracing (repetitive spikes, spike-and-wave discharges, or slow waves) lasting at least 5 seconds.

The seizure thresholds of 6- and 12-month-old WT and Tau22 mice were assessed with escalating doses of PTZ ( $n=10 /$ genotype/ age). PTZ (Sigma P6500) was dissolved at $3.5 \mathrm{mg} / \mathrm{kg}$ in sterile $0.9 \%$ $\mathrm{NaCl}$ and delivered i.p. with a starting dose of $20 \mathrm{mg} / \mathrm{kg}$, followed by additional doses of $5 \mathrm{mg} / \mathrm{kg}$ every 5 minutes. During each 5 -min period, mice were evaluated for the presence of Straub's tail, clonic convulsions, hindlimb extension, and death. Data are expressed as survival curves with the percentage of nonresponding mice for each evaluation plotted relative to dose.

Western blots and histopathological evaluations and quantifications were performed in a separate group of animals as described (Gouder et al., 2004; Laurent et al., 2017; Leboucher et al., 2013). For Western blots, we used anti-GFAP (1:1000; Santa Cruz), anti-ADK (1:4000), and anti-GAPDH (1:10,000; Santa Cruz) antibodies $(\mathrm{n}=$ 3 genotype/age). For the histopathological evaluation, mice were transcardially perfused with $0.9 \%$ saline and $4 \%$ paraformaldehyde, brains cut into $40 \mu \mathrm{m}$ coronal sections. Immunohistochemical detection of either GFAP (1:15,000; Chemicon International), ADK
(1:5000) or pathological Tau (AT100; $1 / 400$ ) was performed as previously published (Burnouf et al., 2013; Studer et al., 2006).

Quantitative real-time PCR was performed as described (Burnouf et al., 2013). Primer sequences used are as follows: 5' tgtagctgacatctgcaaaaa-3' (GAD65 forward), 5' -gggacatcagtaaccctcca-3' (GAD65 reverse), 5'-agcatacaggtcctggcatc-3' (cyclophilin A forward), 5'-ttcaccttcccaaagaccac-3' (cyclophilin A reverse). Cyclophilin A was used as internal control. Amplifications were carried out in triplicate and the relative expression of target genes was determined by the $\Delta \Delta C T$ method.

For microdialysate analysis of hippocampal GABA, 12-month-old Tau22 mice $(n=6)$ or WT $(n=8)$ were anesthetized with urethane $(1.62 \mathrm{~g} / \mathrm{kg} /$ i.p. $)$ and placed in a stereotaxic frame (David Kopf) with the body temperature maintained close to $37.5^{\circ} \mathrm{C}$ using a heated under-blanket (Harvard Instruments, USA). Homemade microdialysis probes with a $1-\mathrm{mm}$ regenerated cellulose membrane (NeuroDialyTics facility, Lyon Neuroscience Research Center, France) was randomly implanted in the right or left dorsal hippocampus (AP $-1.8 \mathrm{~mm}, \mathrm{ML} \pm 1.5 \mathrm{~mm}, \mathrm{DV}-2.4 \mathrm{~mm}$ ). Probes were perfused at a rate of $1 \mu \mathrm{L} / \mathrm{min}$ with artificial cerebrospinal fluid (aCSF) (149 mM NaCl, $2.80 \mathrm{mM} \mathrm{KCl}, 1.2 \mathrm{mM} \mathrm{MgCl}$, $1.2 \mathrm{mM} \mathrm{CaCl}_{2}$, $2.78 \mathrm{mM}$ phosphate buffer, $\mathrm{pH}$ 7.4). At least 2 hours elapsed before collection of basal samples (fractions 1, 2, and, 3), collected every five minutes. In situ depolarization was induced for 15 minutes (fractions 4, 5, and, 6) in both groups by switching the inlet of the probe with a aCSF containing a high concentration of potassium (51.8 mM NaCl, $100 \mathrm{mM} \mathrm{KCl}, 1.2 \mathrm{mM} \mathrm{MgCl}_{2}, 1.2 \mathrm{mM} \mathrm{CaCl}_{2}, 2.78 \mathrm{mM}$ phosphate buffer, $\mathrm{pH}$ 7.4). Fractions 7 to 10 corresponded to perfusion with normal aCSF for washing and return to baseline. At the end of the experiment, the placement of the cannula was verified on the frozen hemisphere. Collected dialysates were stored and kept at $-80^{\circ} \mathrm{C}$ before analyses, performed using capillary electrophoresis with laser-induced fluorescence detection (Sauvinet et al., 2003).

Data were analyzed using GraphPad Prism software (GraphPad Software, La Jolla, CA, USA) using Student's $t$, two-way ANOVA followed by Bonferroni post-hoc analysis and Mantel-Cox (Logrank) test for the survival curves. The null hypothesis was rejected at the $p=0.05$ level for all analyses.

\section{Results}

We first determined if Tau pathology is sufficient to elicit spontaneous seizures. In the THY-Tau22 strain, hippocampal pathology substantially progresses from 6 to 12 months of age (Schindowski et al., 2006). Importantly, at the age of 6 months, THYTau22 mice do not exhibit spatial memory impairments while at 12 months, these mice show significant alterations (Burnouf et al., 2013; Carvalho et al., 2019; Van der Jeugd et al., 2013). EEG recordings obtained from hippocampal depth electrodes implanted into the CA1 of 6- and 12-month-old mice were found to be similar to the brain activity of WT littermates (Fig. 1). Cumulative recording times of at least 500 hours did not reveal a single electrographic seizure. EEGs were without changes in the spike waveform that are indicative of spontaneous electrographic seizures or epileptiform activity (Fig. 1A and F). Despite a lack of spontaneous electrographic seizures in the mutant mice, Tau pathology led to a moderate increase in seizure susceptibility (Fig. 1B-D). Using the PTZ seizure threshold test, overall, THY-Tau22 mice progressed from Straub's tail (Fig. 1B and G), to clonus extension (Fig. 1C and $\mathrm{H}$ ) and finally hindlimb extension (Fig. 1D and I) at a lower dose of PTZ than WT littermates. There was also a trend toward increased mortality in the Tau22 mice (Fig. 1E and I). Therefore, Tau pathology increases seizure susceptibility, although insufficient to cause epileptic seizures by itself. Several mechanisms may be involved in the 
A

\begin{tabular}{|c|}
\hline 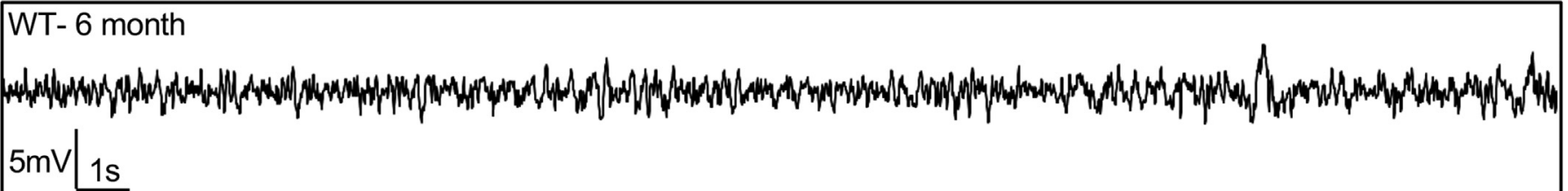 \\
\hline
\end{tabular}
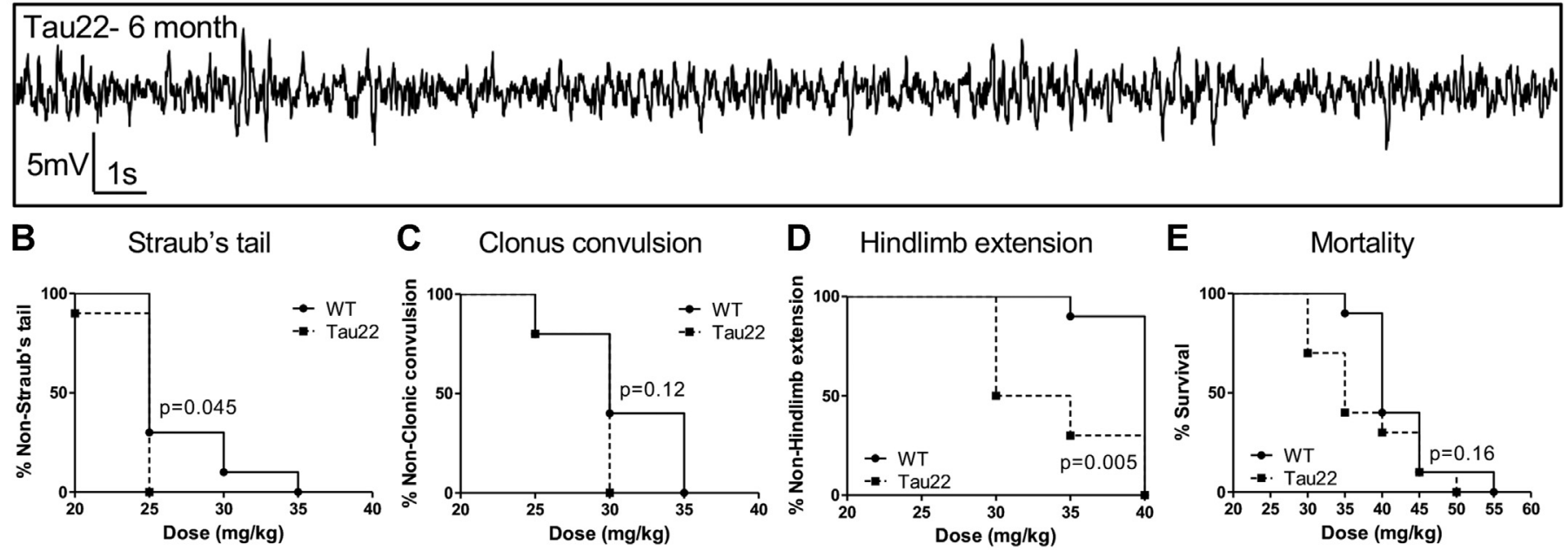

$\mathbf{F}$
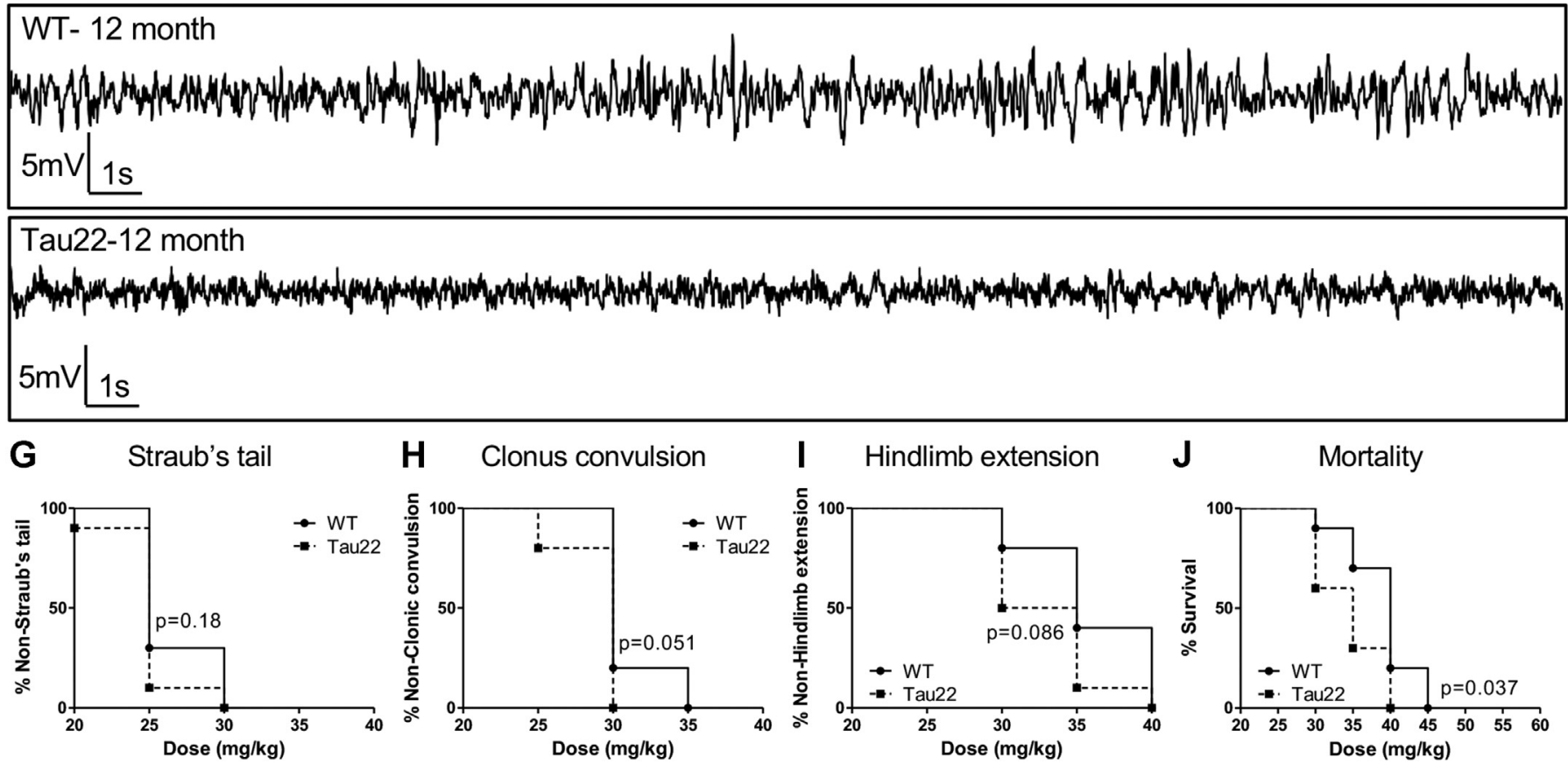

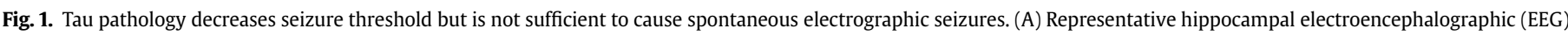

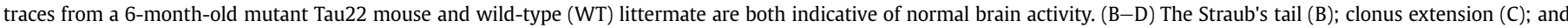

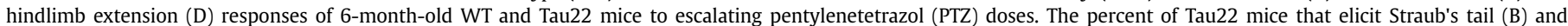

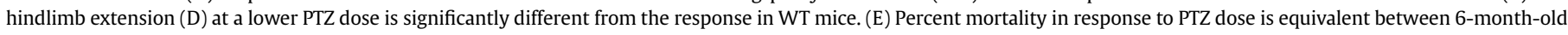

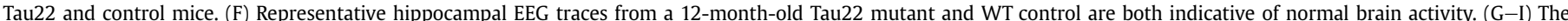

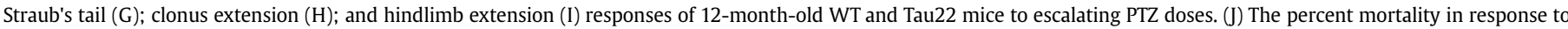

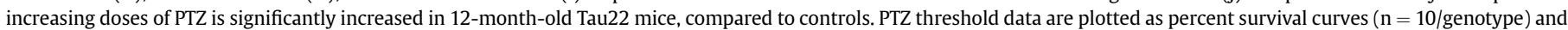
analyzed with a Mantel-Cox (log-rank) test.

increased seizure susceptibility to PTZ. Here, we sought to investigate if Tau pathology modulates the expression of markers typically associated with network hyperexcitability and seizures such as astrocytic and GABA-related markers. First, we identified a significant hippocampal increase of the astrogliosis marker GFAP at both 6 and 12 months of age in Tau mice (Fig. 2A-C). This coincided with a delayed increase in adenosine kinase (ADK) expression in transgenic animals (Fig. 2D-F). Noteworthy, Tau pathology, as marked by the conformational AT100 antibody, is significantly enhanced between these 2 time points (Fig. 2G-I). In addition, while we found a 
A
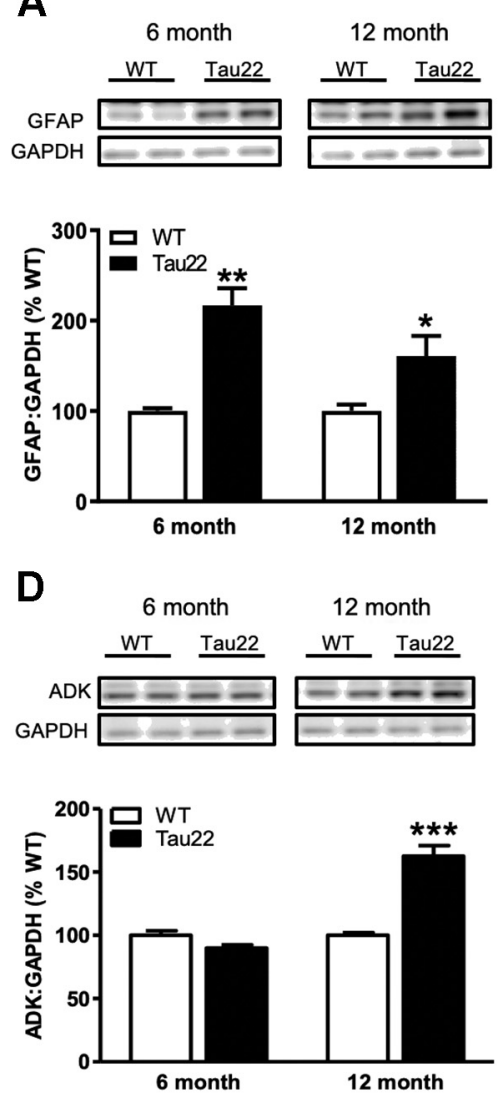
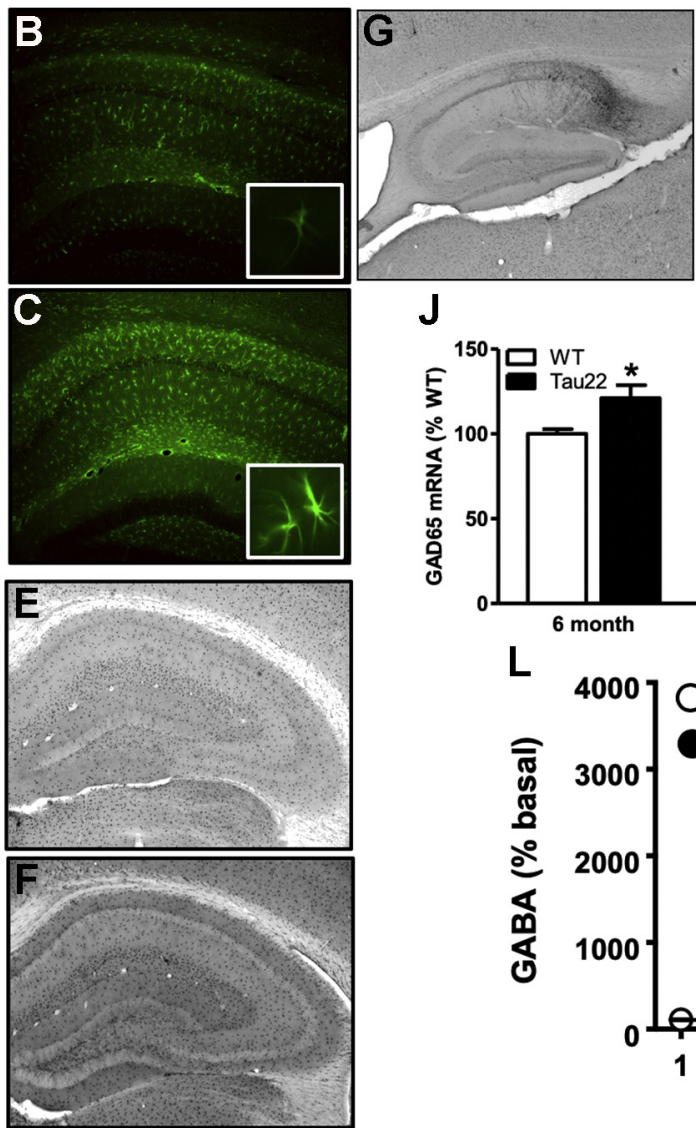

$\mathbf{L}$

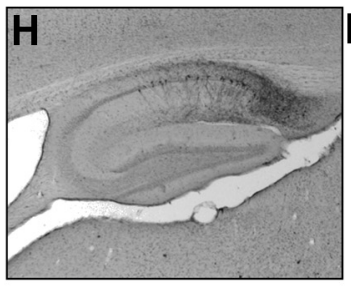

$\mathrm{K}$
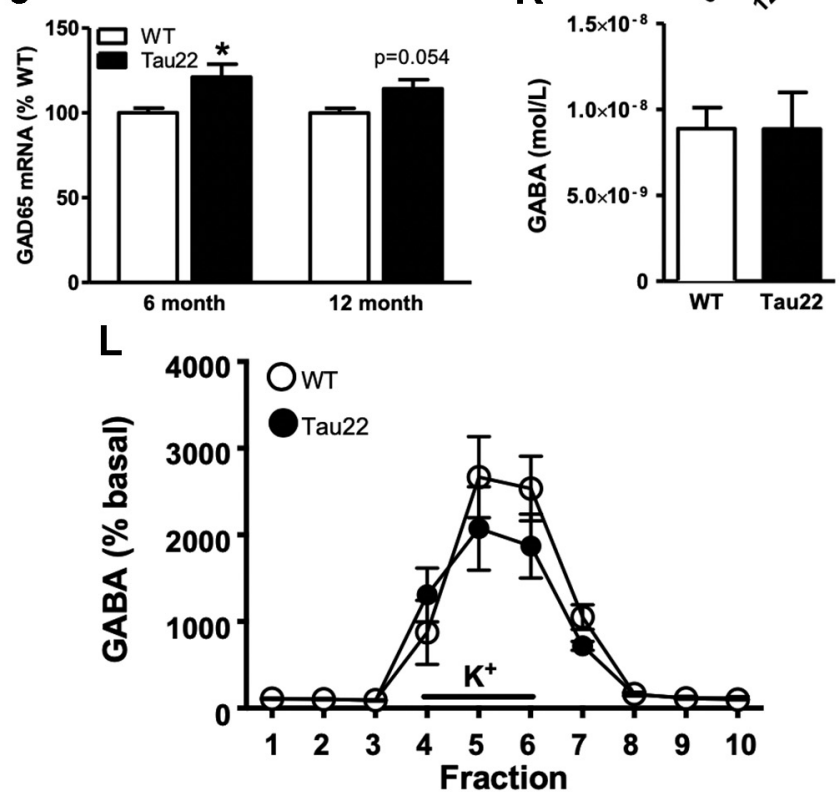

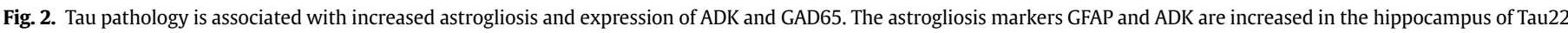

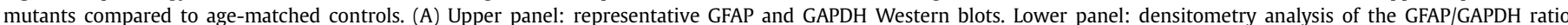

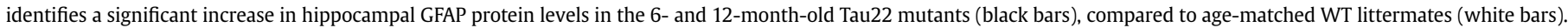

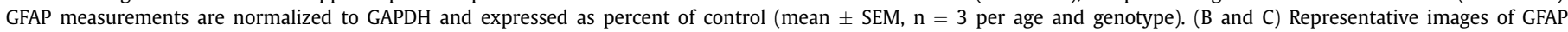

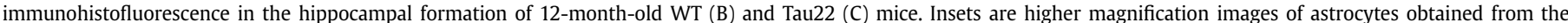

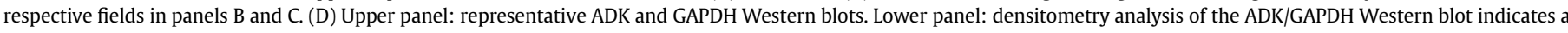

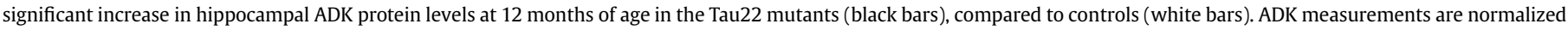

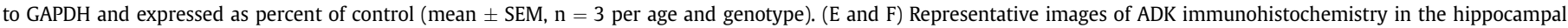

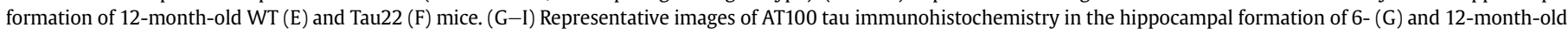

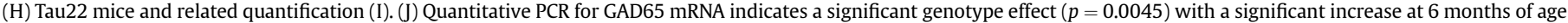

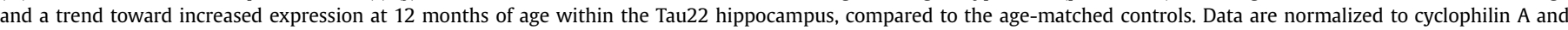

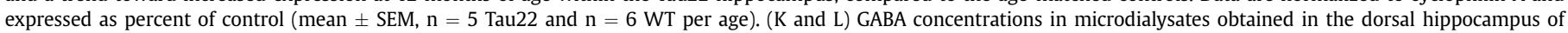

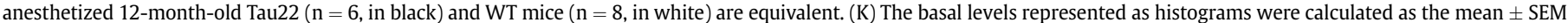

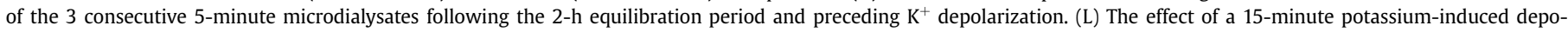

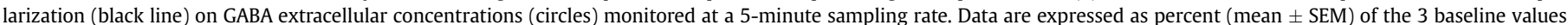

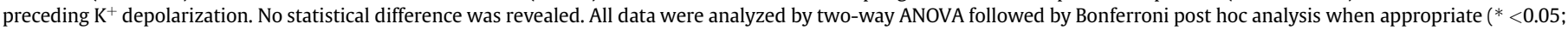
** $<0.01,{ }^{* * *}<0.0001$ ).

moderate increase in GAD65 expression in THY-Tau22 as compared to WT (Fig. 2J), basal GABA levels revealed no statistical difference between WT and Tau22 mice (Fig. 2K). Furthermore, responses to potassium-induced depolarization were also examined; and in spite of a downward trend, the release of GABA induced by $100 \mathrm{mmol} / \mathrm{L} \mathrm{K}^{+}$for Tau 22 mice was not statistically different from that in WT mice (Fig. 2L).

\section{Discussion}

Accumulation of $A \beta$ into plaques and Tau in neurofibrillary degeneration are the 2 hallmarks of $A D$. While the role of $A \beta$ into the development of $\mathrm{AD}$-related seizures has been well investigated (reviewed in the study by Vossel et al., 2017), the involvement of Tau pathology, and relationship to memory impairments remained ill-defined. Here, we used the progressive THY-Tau22 strain to investigate the link between Tau pathology development, hippocampal memory deficits and seizure occurrence, as well as susceptibility to PTZ. Evaluations were performed at 6 months of age, when pathology is present, but memory unaffected, and 12 months of age when hippocampal pathology and memory impairments culminate (Van der Jeugd et al., 2013). Moreover, during this period, neuroinflammation, a known contributor to the pathophysiology of epilepsy (Vezzani et al., 2019), is ongoing and participate to memory deficits (Ising et al., 2019; Laurent et al., 2016, 2017).

Our results suggest that established Tau pathology unlikely leads to spontaneous seizure occurrence. However, the PTZ data indicate that Tau pathology reduced seizure threshold as early as 6 months, when hippocampal-dependent memory is not impaired. It seems unlikely that susceptibility to PTZ relates to Tau pathology itself. Indeed, while the latter is substantially enhanced between 6 and 12 months of age in the THY-Tau22 strain, this does not lead to a particular enhancement of susceptibility to PTZ. Excitability 
changes might therefore relate to either soluble toxic species and/or Tau overexpression as previously suggested in another transgenic Tau model (Maeda et al., 2016). Several mechanisms could be involved in the observed increased seizures susceptibility (reviewed in the study by Vossel et al., 2017), such as glutamate spillover that may occur through impaired glial transporters and/or impaired presynaptic release, alterations of GABA or GABAergic interneurons, or metabolism of the endogenous anticonvulsant adenosine through astrocytic ADK. In a former study, we demonstrated that THY-Tau22 mice exhibit increased hippocampal levels of glutamate (Laurent et al., 2016) and an increase in the glutamatergic drive in CA1 (Zappettini et al., 2019), which might be implicated in the increased susceptibility to PTZ found in Tau mice. Conversely, while Tau mice exhibit a slight change in GAD mRNA expression, steady-state and induced GABA levels were not found altered in Tau mice, presumably excluding an involvement in the PTZ phenotype.

Interestingly, we found that PTZ sensitivity was associated with a significant increase in astroglial ADK levels at 12 months of age. Increased levels of ADK are a pathological hallmark of both epilepsy and AD (Aronica et al., 2013). It has also been documented that increased levels of ADK can be a direct cause for the generation of spontaneous electrographic seizures (Li et al., 2008). The lack of spontaneous electrographic seizures in the THY-Tau22 mice was therefore an unexpected finding. However, we found a reduction of PTZ seizure thresholds, which is in line with increased ADK expression and a concomitant reduction of the inhibitory adenosinergic tone.

Overall, our results show that THY-Tau22 pathology is not sufficient to generate spontaneous subclinical seizures, but our results clearly show that the THY-Tau22 pathology can reduce seizure thresholds independently of $A \beta$. In contrast to Tau models, previous data from transgenic amyloidogenesis models clearly demonstrate the occurrence of spontaneous seizures (Minkeviciene et al., 2009; Palop et al., 2007). Reasons for such discrepancy remain unclear, but it may potentially depend on the enhanced ability of amyloid peptides and plaques to promote microglia and astrocytic neuroinflammation (Sierksma et al., 2020) known to strongly contribute to seizure development (Vezzani et al., 2011), as well as to memory impairments (Ising et al., 2019; Laurent et al., 2017). Further, amyloid- $\beta$ induced seizures depend on the presence of tau (Roberson et al., 2007), suggesting that the development of Tau pathology may further aggravate $A \beta$-driven seizures in $A D$.

\section{Disclosure statement}

The authors declare no conflict of interest.

\section{CRediT authorship contribution statement}

Victoria Gomez-Murcia: Methodology, Formal analysis, Writing - original draft, Writing - review \& editing. Ursula Sandau: Methodology, Formal analysis, Writing - original draft, Writing - review \& editing. Barbara Ferry: Methodology, Formal analysis, Writing original draft, Writing - review \& editing. Sandrine Parrot: Methodology, Formal analysis, Writing - original draft, Writing - review \& editing. Cyril Laurent: Methodology, Formal analysis, Writing original draft, Writing - review \& editing. Marie Basquin: Methodology. Luc Buée: Writing - review \& editing. Detlev Boison: Conceptualization, Formal analysis, Writing - original draft, Writing - review \& editing. David Blum: Conceptualization, Formal analysis, Writing - original draft, Writing - review \& editing.

\section{Acknowledgements}

The authors thank the Animal Facility (F-59000 Lille, France) and Melanie Besegher, Cyrille Degraeve, Caroline Declerck, Kim Letten, Yann Lepage, Benjamin Guerrin, Didier Montignies, Christian Meunier, Quentin Dekeyser, and Romain Dehaynin for animal care.

This work was supported by grants from Hauts-de-France (PARTEN-AIRR, COGNADORA), ANR (ADORASTrAU to DBl), CoEN \#5008 and Programs d'Investissements d'Avenir LabEx (excellence laboratory) DISTALZ (Development of Innovative Strategies for a Transdisciplinary approach to ALZheimer's disease). Our laboratories are also supported by Fondation pour la Recherche Médicale, France Alzheimer/Fondation de France, FHU VasCog research network (Lille, France), Fondation Vaincre Alzheimer, Fondation Plan Alzheimer as well as Inserm, CNRS, Université Lille, Lille Métropole Communauté Urbaine, DN2M. VG-M was supported by Fondation pour la Recherche Médicale (SPF20160936000). DBo is funded through grants from the US National Institutes of Health (NIH, NS103740, NS065957), the CURE foundation (CURE Catalyst Award), and the New Jersey Commission for Brain Injury Research.

\section{References}

Arendt, T., Stieler, J.T., Holzer, M., 2016. Tau and tauopathies. Brain Res. Bull. 126 (Pt 3), 238-292.

Aronica, E., Sandau, U.S., Iyer, A., Boison, D., 2013. Glial adenosine kinase-a neuropathological marker of the epileptic brain. Neurochem. Int. 63, 688-695.

Bejanin, A., Schonhaut, D.R., La Joie, R., Kramer, J.H., Baker, S.L., Sosa, N., Ayakta, N. Cantwell, A., Janabi, M., Lauriola, M., O'Neil, J.P., Gorno-Tempini, M.L., Miller, Z.A Rosen, H.J., Miller, B.L., Jagust, W.J., Rabinovici, G.D., 2017. Tau pathology and neurodegeneration contribute to cognitive impairment in Alzheimer's disease. Brain 140, 3286-3300.

Brier, M.R., Gordon, B., Friedrichsen, K., McCarthy, J., Stern, A., Christensen, J., Owen, C., Aldea, P., Su, Y., Hassenstab, J., Cairns, N.J., Holtzman, D.M., Fagan, A.M. Morris, J.C., Benzinger, T.L., Ances, B.M., 2016. Tau and A $\beta$ imaging., CSF measures., and cognition in Alzheimer's disease. Sci. Transl. Med. 8, 338ra66.

Burnouf, S., Martire, A., Derisbourg, M., Laurent, C., Belarbi, K., Leboucher, A., Fernandez-Gomez, F.J., Troquier, L., Eddarkaoui, S., Grosjean, M.E., Demeyer, D., Muhr-Tailleux, A., Buisson, A., Sergeant, N., Hamdane, M., Humez, S., Popoli, P., Buée, L., Blum, D., 2013. NMDA receptor dysfunction contributes to impaired brain-derived neurotrophic factor-induced facilitation of hippocampal synaptic transmission in a Tau transgenic model. Aging Cell 12, 11-23.

Carvalho, K., Faivre, E., Pietrowski, M.J., Marques, X., Gomez-Murcia, V., Deleau, A Huin, V., Hansen, J.N., Kozlov, S., Danis, C., Temido-Ferreira, M., Coelho, J.E., Mériaux, C., Eddarkaoui, S., Gras, S.L., Dumoulin, Cellai L, L., NeuroCEB Brain Bank, Landrieu, I., Chern, Y., Hamdane, M., Buée, L., Boutillier, A.L., Levi, S., Halle, A., Lopes, L.V., Blum, D., 2019. Exacerbation of C1q dysregulation, synaptic loss and memory deficits in tau pathology linked to neuronal adenosine A2A receptor. Brain 142, 3636-3654.

Colin, M., Dujardin, S., Schraen-Maschke, S., Meno-Tetang, G., Duyckaerts, C., Courade, J.P., Buée, L., 2020. From the prion-like propagation hypothesis to therapeutic strategies of anti-tau immunotherapy. Acta Neuropathol. 139, 3-25.

DeVos, S.L., Goncharoff, D.K., Chen, G., Kebodeaux, C.S., Yamada, K., Stewart, F.R. Schuler, D.R., Maloney, S.E., Wozniak, D.F., Rigo, F., Bennett, C.F., Cirrito, J.R., Holtzman, D.M., Miller, T.M., 2013. Antisense reduction of tau in adult mice protects against seizures. J. Neurosci. 33, 12887-12897.

Duyckaerts, C., Bennecib, M., Grignon, Y., Uchihara, T., He, Y., Piette, F., Hauw, J. 1997. Modeling the relation between neurofibrillary tangles and intellectual status. Neurobiol. Aging 18, 267-273.

García-Cabrero, A.M., Guerrero-López, R., Giráldez, B.G., Llorens-Martín, M., Avila, J. Serratosa, J.M., Sánchez, M.P., 2013. Hyperexcitability and epileptic seizures in a model of frontotemporal dementia. Neurobiol. Dis. 58, 200-208.

Gouder, N., Scheurer, L., Fritschy, J.-M., Boison, D., 2004. Overexpression of adenosine kinase in epileptic hippocampus contributes to epileptogenesis. J. Neurosci. 24, 692-701.

Gheyara, A.L., Ponnusamy, R., Djukic, B., Craft, R.J., Ho, K., Guo, W., Finucane, M.M. Sanchez, P.E., Mucke, L., 2014. Tau reduction prevents disease in a mouse model of Dravet syndrome. Ann. Neurol. 76, 443-456.

Guo, T., Noble, W., Hanger, D.P., 2017. Roles of tau protein in health and disease. Acta Neuropathol. 133, 665-704.

Holth, J.K., Bomben, V.C., Reed, J.G. Inoue, T. Younkin, L. Younkin, S.G., Pautler, R.G. Botas, J., Noebels, J.L., 2013. Tau loss attenuates neuronal network hyperexcitability in mouse and drosophila genetic models of epilepsy. J. Neurosci. 33 $1651-1659$.

Ising, C., Venegas, C., Zhang, S., Scheiblich, H., Schmidt, S.V., Vieira-Saecker, A., Schwartz, S., Albasset, S., McManus, R.M., Tejera, D., Griep, A., Santarelli, F., Brosseron, F., Opitz, S., Stunden, J., Merten, M., Kayed, R., Golenbock, D.T. 
Blum, D., Latz, E., Buée, L., Heneka, M.T., 2019. NLRP3 inflammasome activation drives tau pathology. Nature 575, 669-673.

Ittner L.M., Ke, Y.D., Delerue, F, Bi, M. Gladbach, A, van Eersel, J, Wölfing, $\mathrm{H}$, Chieng, B.C., Christie, M.J., Napier, I.A., Eckert, A., Staufenbiel, M., Hardeman, E., Götz, J., 2010. Dendritic function of tau mediates amyloid-beta toxicity in Alzheimer's disease mouse models. Cell 142, 387-397.

Lam, A.D., Deck, G., Goldman, A., Eskandar, E.N., Noebels, J., Cole, A.J., 2017. Silent hippocampal seizures and spikes identified by foramen ovale electrodes in Alzheimer's disease. Nat. Med. 23, 678-680.

Laurent, C., Dorothée, G., Hunot, S., Martin, E., Monnet, Y., Duchamp, M., Dong, Y., Légeron, F.P., Leboucher, A., Burnouf, S., Faivre, E., Carvalho, K., Caillierez, R., Zommer, N., Demeyer, D., Jouy, N., Sazdovitch, V., Schraen-Maschke, S., Delarasse, C., Buée, L., Blum, D., 2017. Hippocampal T cell infiltration promotes neuroinflammation and cognitive decline in a mouse model of tauopathy. Brain 140, 184-200.

Laurent, C., Burnouf, S., Ferry, B., Batalha, V.L., Coelho, J.E., Baqi, Y., Malik, E., Mariciniak, E., Parrot, S., Van der Jeugd, A., Faivre, E., Flaten, V., Ledent, C., D'Hooge, R. Sergeant, N., Hamdane, M., Humez, S. Müller, C.E., Lopes, L.V. Buée, L., Blum, D., 2016. A2A adenosine receptor deletion is protective in a mouse model of Tauopathy. Mol. Psychiatry 21, 97-107.

Leboucher, A., Laurent, C., Fernandez-Gomez, F.J., Burnouf, S., Troquier, L., Eddarkaoui, S., Demeyer, D., Caillierez, R., Zommer, N., Vallez, E., Bantubungi, K., Breton, C., Pigny, P., Buée-Scherrer, V., Staels, B., Hamdane, M., Tailleux, A., Buée, L., Blum, D., 2013. Detrimental effects of diet-induced obesity on $\tau$ pathology are independent of insulin resistance in $\tau$ transgenic mice. Diabetes 62, 1681-1688.

Lebouvier, T., Pasquier, F., Buée, L., 2017. Update on tauopathies. Curr. Opin. Neurol. 30, 589-598.

Li, T., Ren, G., Lusardi, T., Wilz, A., Lan, J.Q., Iwasato, T., Itohara, S., Simon, R.P., Boison, D., 2008. Adenosine kinase is a target for the prediction and prevention of epileptogenesis in mice. J. Clin. Invest. 118, 571-582.

Maeda, S., Djukic, B., Taneja, P., Yu, G.Q., Lo, I., Davis, A., Craft, R., Guo, W., Wang, X., Kim, D., Ponnusamy, R., Gill, T.M., Masliah, E., Mucke, L., 2016. Expression of A152T human tau causes age-dependent neuronal dysfunction and loss in transgenic mice. EMBO Rep. 17, 530-551.

Minkeviciene, R., Rheims, S., Dobszay, M.B.,Zilberter, M., Hartikainen, J., Fülöp, L., Penke, B., Zilberter, Y., Harkany, T., Pitkänen, A., Tanila, H., 2009. Amyloid beta-induced neuronal hyperexcitability triggers progressive epilepsy. J. Neurosci. 29, 3453-3462.

Palop, J.J., Chin, J., Roberson, E.D., Wang, J., Thwin, M.T., Bien-Ly, N., Yoo, J., Ho, K.O., Yu, G.Q., Kreitzer, A., Finkbeiner, S., Noebels, J.L., Mucke, L., 2007. Aberrant excitatory neuronal activity and compensatory remodeling of inhibitory hippocampal circuits in mouse models of Alzheimer's disease. Neuron 55, 697-711.

Roberson, E.D., Scearce-Levie, K., Palop, J.J., Yan, F., Cheng, I.H., Wu, T., Gerstein, H. Yu, G.Q., Mucke, L., 2007. Reducing endogenous tau ameliorates amyloid betainduced deficits in an Alzheimer's disease mouse model. Science 316, 750-754.
Sánchez, M.P., García-Cabrero, A.M., Sánchez-Elexpuru, G., Burgos, D.F. Serratosa, J.M., 2018. Tau-induced pathology in epilepsy and dementia: notions from patients and animal models. Int. J. Mol. Sci. 19, 1092.

Sauvinet, V., Parrot, S., Benturquia, N., Bravo-Morato, E., Renaud, B., Denoroy, L. 2003. In vivo simultaneous monitoring of gamma-aminobutyric acid., glutamate., and L-aspartate using brain microdialysis and capillary electrophoresis with laser-induced fluorescence detection: analytical developments and in vitro/in vivo validations. Electrophoresis 24, 3187-3196.

Schindowski, K., Bretteville, A., Leroy, K., Begard, S., Brion, J.P., Hamdane, M., Buee, L. 2006. Alzheimer's disease-like tau neuropathology leads to memory deficits and loss of functional synapses in a novel mutated tau transgenic mouse without any motor deficits. Am. J. Pathol. 169, 599-616.

Sergeant, N., Bretteville, A., Hamdane, M., Caillet-Boudin, M.L., Grognet, P. Bombois, S., Blum, D., Delacourte, A., Pasquier, F., Vanmechelen, E., SchraenMaschke, S., 2008. Biochemistry of Tau in Alzheimer's disease and related neurological disorders. Expert Rev. Proteomics 5, 207-224.

Sierksma, A., Lu, A., Mancuso, R., Fattorelli, N., Thrupp, N., Salta, E. Zoco, J., Blum, D. Buée, L., De Strooper, B., Fiers, M., 2020. Novel Alzheimer risk genes determine the microglia response to amyloid- $\beta$ but not to TAU pathology. EMBO Mol. Med. 12, e10606.

Studer, F.E., Fedele, D.E., Marowsky, A., Schwerdel, C., Wernli, K., Vogt, K. Fritschy, J.M., Boison, D., 2006. Shift of adenosine kinase expression from neurons to astrocytes during postnatal development suggests dual functionality of the enzyme. Neuroscience 142, 125-137.

Van der Jeugd, A., Vermaercke, B., Derisbourg, M., Lo, A.C., Hamdane, M., Blum, D. Buée, L., D'Hooge, R., 2013. Progressive age-related cognitive decline in tau mice. J. Alzheimers Dis. 37, 777-788.

Van Erum, J., Valkenburg, F., Van Dam, D., De Deyn, P.P., 2020. Pentylenetetrazoleinduced seizure susceptibility in the tau58/4 transgenic mouse model of tauopathy. Neuroscience $425,112-122$.

Vezzani, A., Balosso, S., Ravizza, T., 2019. Neuroinflammatory pathways as treatment targets and biomarkers in epilepsy. Nat. Rev. Neurol. 15, 459-472.

Vezzani, A., French, J., Bartfai, T., Baram, T.Z., 2011. The role of inflammation in epilepsy. Nat. Rev. Neurol. 7, 31-40.

Vossel, K.A., Tartaglia, M.C., Nygaard, H.B., Zeman, A.Z., Miller, B.L., 2017. Epileptic activity in Alzheimer's disease: causes and clinical relevance. Lancet Neurol. 16, $311-322$.

Wang, Y., Mandelkow, E., 2016. Tau in physiology and pathology. Nat. Rev. Neurosci. $17,5-21$.

Zappettini, S., Faivre, E., Ghestem, A., Carrier, S., Buée, L., Blum, D., Esclapez, M. Bernard, C., 2019. Caffeine consumption during pregnancy accelerates the development of cognitive deficits in offspring in a model of tauopathy. Front. Cell Neurosci. 13, 438. 